\title{
An Unhealthy Buying Pattern of the Peoples of Bangladesh: A Case of Tobacco \& Beverage
}

\author{
Ahnaf Chowdhury Niloy \\ Department of Business Administration, East West University, Dhaka, BANGLADESH \\ *E-mail for correspondence: ahnafniloy@outlook.com \\ $\underline{\text { https://doi.org/10.18034/abr.v10i3.509 }}$
}

\begin{abstract}
Bangladesh is a comparatively small country but a densely populated country that has attracted several big companies to come and run their business including carbonated drinks and tobacco. International beverage brands like coca-cola, Pepsi, etc., and tobacco brands like British American Tobacco, Philip Morris International, etc. are doing great business in Bangladesh alongside local brands. Even though for business, these products are a must but when it comes to health issues these are such products that affect physically greatly. Matter of consciousness comes when the consumer is giving preference to such products more than essential consumables that are seen in Bangladesh. The paper discusses the consumer behavior of Bangladeshi consumers in choosing products in terms of health benefits. The paper is an original work of the author and all the secondary data were taken are given credits properly.
\end{abstract}

Key words: Beverage, Buying Pattern, Carbonates, Tobacco

\section{INTRODUCTION}

Bangladesh is a densely populated country that is attractive to several international companies including local brands. About 1265 people live in per square kilometers in Bangladesh (Worldometer, 2020). Bangladesh also has a per capita GDP at PPP of USD 4950 (The World Bank, 2020). Like many other brands, beverage giants like Coca Cola came to Bangladesh in 1965 (Russell, 2012). After the partition, in 1949, Pakistan Tobacco Company was established (British American Tobacco Bangladesh, 2020). The consumption of cigarettes and carbonated soft drinks has been on a rise in recent years and the prediction tells it will be on a rise. The impact of coronavirus did affect the business of tobacco in Bangladesh, but as time is passing it is getting back to where it was.

\section{Methodology}

The research methodology followed is archival research. For the analysis, the data is collected from Marketline Database that has actual data of 2018 - 2019, and forecasted data of 2020 - 2024. The data is shown using line charts and the overall discussion is showcased in an exploratory manner. The detailed citations are added at the end of the paper.

\section{SignificANCE OF THE STUdY}

The study provides a significant finding that can attract health concern product manufacturers on promotional activities and campaign designing. The study findings can also benefit FMCG firms on taking decision on developing products that can be focused based upon health consciousness. The study is significant in taking economic and business decisions by government and firms. The study also provides a clear idea of the market attractiveness and average buying pattern of the highlighted consumer goods.

\section{LITERATURE REVIEW}

Consumption of tobacco is highly injurious to health that is known to all. But though ignorant behavior in consumption of carbonated drinks are seen in Bangladeshi consumers, it is also injurious to health as carbonated drinks possess high level sugar that is the reason of several health diseases. From 1980 to 2017 obesity rose from 7\% to 17\% in Bangladesh among adults (Salahuddin, 2018). Tobacco murdered almost 126,000 individuals in Bangladesh in 2018, representing $13.5 \%$ of all passing in the nation, presently about 1.5 million grown-ups experiencing 
tobacco-inferable sickness in Bangladesh and in excess of 61,000 youngsters (beneath age 15) are experiencing infections brought about by introduction to used smoke (Faruque et al., 2020). As indicated by the investigation, the joined overweight and stoutness rate among ghetto occupants in the capital is $39.2 \%$ for ladies and $18.9 \%$ for men and public average is $16.4 \%$ in men and $24.2 \%$ in ladies (Amin, 2019). Another research shows that about among 600 randomly selected young school-aged children (6-17 years, both boys and girls) from the six English Medium schools in Dhaka city of Bangladesh $48 \%$ of the school children consumed soft drinks regularly (Shahjahan et al., 2019). The GATS found that $23.0 \%$ of grown-ups matured 15 years or above were smokers of tobacco in Bangladesh (for guys $44.7 \%$ and for females 1.5\%). The NCD Risk Factor Survey watched $26.2 \%$ generally speaking smoking predominance- $54.8 \%$ for men and $1.3 \%$ for ladies (Nargis et al., 2015). Younger people are more inspired rather the older ones in case of tobacco consumption and higher educated people tend have more tobacco consumption trend of smokeless tobacco than less educated consumers (Sultana, et al., 2017). Study has also found that university going Bangladeshi students consume carbonated drinks more and the main purpose behind greater consumption is the belief of tiredness removal (Islam \& Habib, 2009). A study in Mymensingh revealed that $40 \%$ aged between 1517 smokes whose family income per month is below \$260 (Rahman \& Tareque, 2020). According to a survey, among 43 countries Bangladesh was $3^{\text {rd }}$ in terms of tobacco consumption (D'Angelo et al., 2016).

\section{ANALYSIS}

For understanding the buying behavior, the categories considered for comparison are - Food, Carbonated Beverage and Tobacco. The food category contains 15 markets which are-

- $\quad$ Bakery \& Cereal

- Beans and Pulses

- Confectionery

- Dairy and Soy Food

- Fish and Seafood

- Ice Cream

- Meat

- Meat Substitutes

- Oils and Fats

- Pasta and Noodles

- Prepared Meals

- Savory Snacks

- Seasoning, Dressing and Sauces

- Soups

- Syrups \& Spreads

In case of Tobacco, the markets considered are -

- $\quad$ Filtered Cigarettes

- Unfiltered Cigarettes

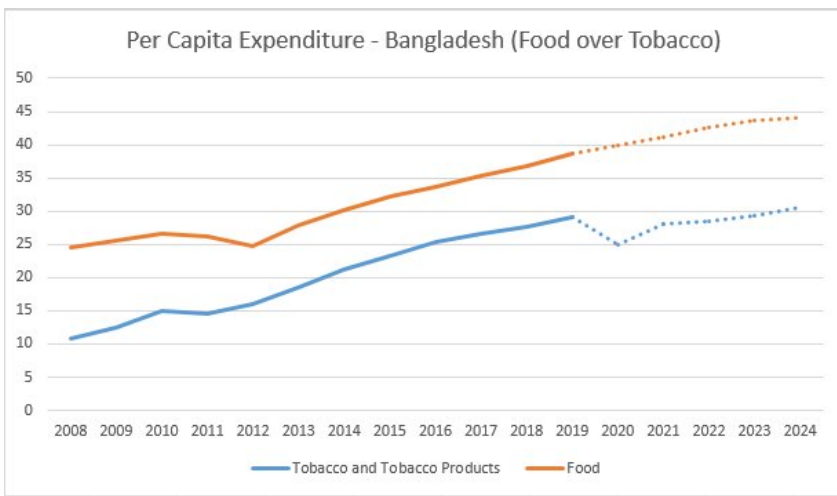

Figure 1. Per Capita Expenditure of Food and Tobacco from 2008-2019 (Actual) and till 2024 (Projected).

The graph clearly shows that Bangladeshi consumers tend to spend a great amount of money on just a single product - tobacco compared to food that consists of 15 different markets. The analysis is far clearer in the next graphical representations.

For deeper understanding, only four core consumable elements were compared - milk, chicken, beef and fish. The results say that milk is the market in which Bangladeshi consumers tend to spend comparatively more (Figure 2). But Figure 3 will give a much clearer explanation that the consumers of Bangladesh tend to spend way more in tobacco compared to milk.

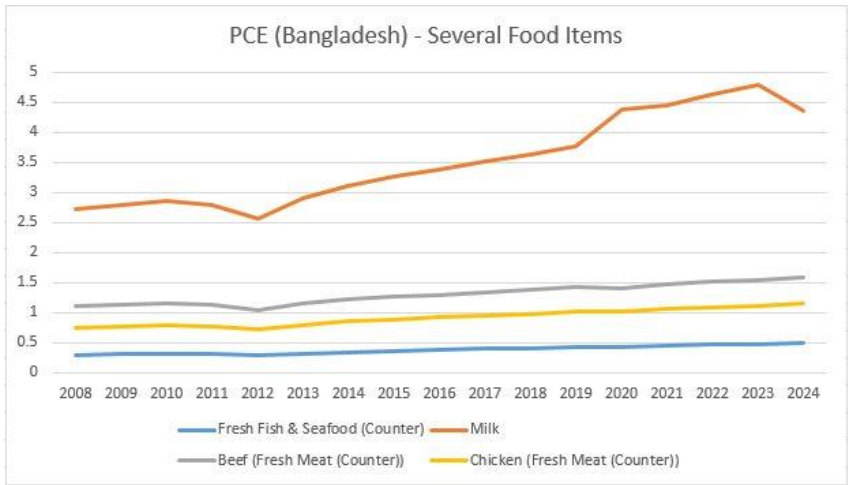

Figure 2. PCE of Milk, Fish, Beef and Chicken in Bangladesh from 2008-2019 (Actual) and till 2024 (Projected).

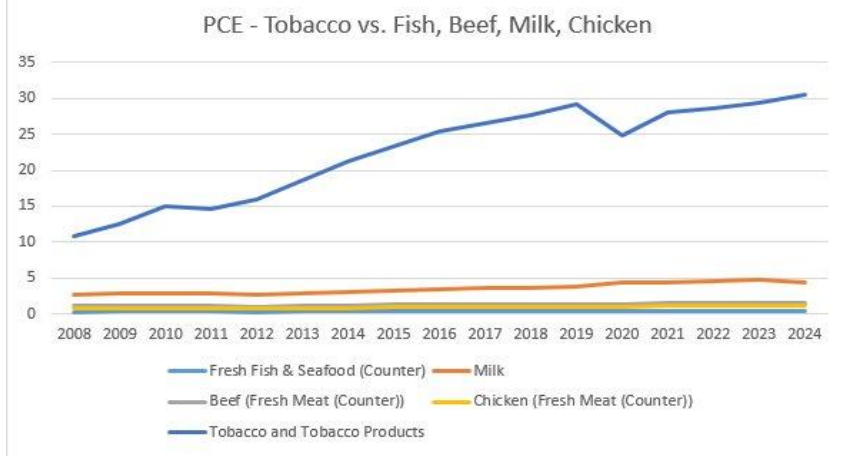

Figure 3. PCE of Milk, Fish, Beef and Chicken in Bangladesh from 2008-2019 (Actual) and till 2024 (Projected). 
The above graphical representations describe the pattern of tobacco consumption. However, carbonated drinks' graphical representation shows the alarming state how consumers tend to choose carbonated drinks over the ideal drink - Milk (Figure 4).

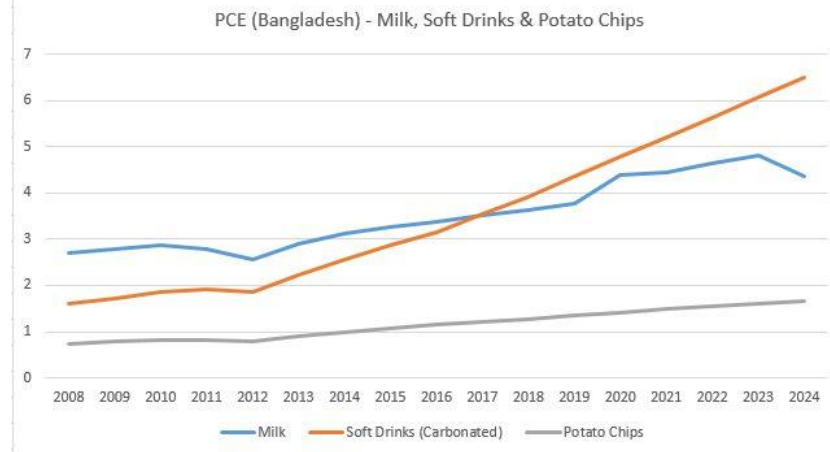

Figure 4. PCE of Carbonated Drinks, Milk and Potato Chips in Bangladesh from 2008-2019 (Actual) and till 2024 (Projected).

The graph clearly shows after 2017, PCE of carbonated drinks surpassed milk and prediction tells that PCE of carbonated drinks is on a continuous rise. Interestingly if Figure 4 is compared with Figure 2, it is also seen that PCE of Potato Chips is higher than PCE of chicken and fish. The projected value also indicates that it may become near to beef in future as well.

\section{POLICY IMPLICATIONS}

As discussed throughout the text, junk food like tobacco and carbonated drinks has seen a rise in Bangladesh which may be good for business but severely harmful in terms of health consciousness, especially the youngsters. The rise of problems regarding obesity and heart diseases discussed in the literature review section also points out the horrific situation. In case of tobacco, although a number of policy implications have been taken the rise of tobacco consumption is still significant. The author would like to suggest some policy implications that may become helpful to reduce the growth of tobacco and carbonated drinks consumption in Bangladesh. However, as mentioned earlier that from other studies it was found that tobacco and carbonated drinks - both were more popular among the younger generation, thus the author tries to provide policy implications that may be effective to reduce the consumption of this particular age group only.

- Introduction of sports drinks by local brands: The author suggests that, as sports drinks are better than carbonates in terms of energy regeneration, local manufacturers could focus on manufacturing sports drinks and provide effective marketing so that a portion of carbonates consumers may shift from carbonates to sports drinks, which are more health beneficial.

- Impose restrictions and monitor tobacco sales on age group below 18: The author suggests that as a large number of youngsters buy tobacco who are below the age of 18 can be minimized if strong restrictions are imposed and maintained by the government. Both buyer and seller must face hard consequences if tobacco is to be sold to someone below 18 .

- Effectively monitor public smoking of tobacco on School/College/University Areas: As mentioned earlier, a large group of people smoking tobacco belongs to youngsters including school, college or university. An interesting find is that in most university areas, public or private, a specific place entitled as "Tong" or tea stalls are very famous for smoking. The horrific part is that many female students who are not seen smoking in their neighborhood are also seen smoking at the university/college areas. The rising number of female smokers are also a concern as this culture is not acceptable in Bangladesh. The author suggests that university areas should be declared as non-smoking areas so that smoking can be limited and controlled by the authority. Removal of such tea stalls should also take place in order to minimize the supply of tobacco to the students that may reduce the consumption. Strong laws should also be imposed against the students who smoke if found smoking in the area or publicly within the area.

\section{LIMITATIONS}

The research is limited to secondary data sources. The graphical representation of the data although represented by the author, but the numerical values were collected from authentic secondary source. The analysis is also represented through charts only and elaborated in a descriptive manner, rather statistical representation. So the data is not described through any descriptive statistical method. As the data is collected from secondary sources, gender inequality may be present in the data that is not clarified. The study also uses the directly forecasted data collected from the secondary sources as the author did not forecasted the data manually with any accepted models like ARIMA. The secondary data of the study also does not provide the age range of the sample thus the data is considered as a population data. The key focused study of buying pattern identification of tobacco and carbonated drinks is not available in the Bangladeshi context which the author focuses on, thus the author does not cite any articles while describing the core idea and showcased based upon personal justification. The seasonal limitation may also be present in the study as consumption of tobacco and carbonated drinks vary in different seasons.

\section{Conclusion}

It is not an uncommon thing to say that major reasons behind obesity, breathing problems, cancer is the consumption of carbonated drinks and tobacco. A major reason behind the malnourished body structure of many 
Bangladeshi people is not poverty, rather the unhealthy expenditure pattern. With rising tensions of tobacco and carbonated drinks consumption over necessary foods, the future clearly does not seem healthy for the youngsters.

\section{REFERENCES}

Amin, M. A., 2019. Study reveals obesity among urban poor higher than national average. [Online] Available at: https://www.dhakatribune.com/health/2019/01/27/stu dy-reveals-obesity-among-urban-poor-higher-thannational-average

British American Tobacco Bangladesh, 2020. About us. [Online] Available at: http://www.batbangladesh.com/group/sites/BAT 9T5F Q2.nsf/vwPagesWebLive/DO9T5K3S\#

D'Angelo, D. et al., 2016. Current Cigarette Smoking, Access, and Purchases from Retail Outlets Among Students Aged 13-15 Years - Global Youth Tobacco Survey, 45 Countries, 2013 and 2014. Morbidity and Mortality Weekly Report, 65(34), pp. 898-901.

Faruque, G. et al., 2020. The Economic Cost of Tobacco Use in Bangladesh: A Health Cost Approach, Dhaka: American Cancer Society.

Islam, N. \& Habib, W., 2009. A MULTIVARIATE ANALYSIS OF THE SELECTION FACTORS OF CARBONATED SOFT DRINKS IN BANGLADESH. New Orleans, International Academy of Management \& Business (IAMB).

Nargis, N. et al., 2015. Prevalence and Patterns of Tobacco Use in Bangladesh from 2009 to 2012: Evidence from International Tobacco Control (ITC) Study. PLoS One, 11 November.10(11).

Rahman, K. M. M. \& Tareque, M. I., 2020. Determinants of cigarette/bidi smoking among youth male in rural
Mymensingh of Bangladesh: A cross-sectional study.. PLoS ONE, 28 12, 15(12), pp. 1-13.

Russell, M., 2012. Bangladesh: Coca Cola Co to set up Bangladesh Plant - report. [Online] Available at: https://www.just-drinks.com/news/cocacola-co-to-set-up-bangladesh-plant-

report id105910.aspx\#: :text=Currently $\% 2 \mathrm{C} \% 20 \mathrm{Abdul} \% 20$ Monem $\% 20$ and $\% 20$ Pran,an $\% 20$ agreement $\% 20$ with $\% 20 \mathrm{Tab}$ ani\%20Beverage.

Salahuddin, D. T., 2018. Obesity is increasing among the younger generation in Bangladesh. [Online] Available at: https://www.thedailystar.net/health/obesity-increasingin-bangladesh-younger-generation-1637107

Shahjahan, M. et al., 2019. Soft Drink Consumption and its Influence on BMI and Academic Performance among Selected School Children in Dhaka City of Bangladesh. Current Research in Nutrition and Food Science, December, 7(3), pp. 791-799.

Sultana, P., M, T. R. \& Roy, D. C., 2017. Marketing Policy that Accelerate Tobacco Use in Bangladesh: A Statistical Investigation. Journal of Biometrics $\mathcal{E}$ Biostatistics, 8(6), pp. 18.

The World Bank, 2020. GDP per capita, PPP (current international \$) - Bangladesh. [Online] Available at: https://data.worldbank.org/indicator/NY.GDP.PCAP.PP. CD?locations $=\mathrm{BD}$

Worldometer, 2020. Bangladesh Population (LIVE). [Online] Available at: https://www.worldometers.info/worldpopulation/bangladeshpopulation/\#: :text=The $\% 20$ population $\% 20$ density $\% 20$ in \%20Bangladesh,3\%2C277\%20people $\% 20$ per $\% 20 \mathrm{mi} 2$ ).

$--0--$

\section{How to cite this article}

Niloy, A. C. (2020). An Unhealthy Buying Pattern of the Peoples of Bangladesh: A Case of Tobacco \& Beverage. Asian Business Review, 10(3), 167-170. https://doi.org/10.18034/abr.v10i3.509 